\title{
AUTOMUTILAÇÃO DE ADOLESCENTES: UM ESTUDO DE CASO EM ESCOLA PÚBLICA DE FORTALEZA
}

\author{
Automutilation of adolescents: a case study in Fortaleza public school
}

Elaine Marinho Bastos - Unichritus e UniAteneu, Fortaleza/Brasil

\begin{abstract}
RESUMO: A automutilação na adolescência tem ganho atenção de pesquisadores, no entanto o fenômeno ainda é pouco estudado e divulgado em produções científicas, sendo necessária mais ampla pesquisa no intuito de desenvolver ações de prevenção à automutilação. A pesquisa foi realizada em escola pública de Fortaleza, aplicando grupo focal com professores e diretora da escola e os dados encontrados analisadas em seu conteúdo, qualitativamente, trazendo uma maior abrangência, suas características e interfaces, apontando que as condições em que ocorrem a automutilação precisam ser compreendidas a partir dos condicionantes histórico-sociais que perpassam pela experiência de ser adolescente na atualidade. As categorias de discussão foram: As condições do fenômeno, Perfil do adolescer e automutilação e Características da automutilação. Diante da realidade exposta na pesquisa aponta-se a necessidade de ampliar e aprofundar pesquisas sobre a realidade desse contexto por uma variedade de situações e contingências biológicas, familiares, culturais, sociais e históricas.
\end{abstract}

Palavras-chave: Automutilação, Adolescente, Saúde mental.

ABSTRACT: Self-harm in adolescence has gained attention from researchers because of the increase in reported cases in schools and social media. However, the phenomenon is still little studied and disseminated in scientific productions, and further research is needed to develop self-mutilation prevention actions. The research was carried out in a public school in Fortaleza. A focus group with teachers and school principal was applied and the data found analyzed qualitatively, bringing a broader scope about self-mutilation, its characteristics and its interfaces, pointing out that the conditions in that occur selfmutilation need to be understood from the historical-social constraints that permeate the experience of being a teenager today. The discussion categories were: The conditions of the phenomenon, Profile of adolescent and self-mutilation and Characteristics of selfmutilation. Given the reality exposed in the research, it is pointed out the need to broaden and deepen research on the reality of this context, given the complexity of a condition that is influenced by a variety of biological, family, cultural, social and historical situations and contingencies.

Keywords: Self-harm. Adolescent. Mental Health.

\section{INTRODUÇÃO}

A automutilação tem sido considerada um comportamento frequente entre os mais diversos perfis de pessoas na contemporaneidade e tal condição traz vários 
questionamentos para o contexto da saúde pública. Os profissionais da área de saúde mental, bem como profissionais que lidam com perfis diversos, tais como professores, devem ter conhecimento sobre os condicionantes gerais que podem acionar tais autoagressões.

O Manual Diagnóstico e Estatístico de Transtornos Mentais - DSM 5 (APA, 2014) define essa autoagressão como "comportamento repetido do próprio indivíduo de infligir lesões superficiais, embora dolorosas, à superfície do seu corpo" (p.804). Indica ainda que tal comportamento tem como objetivo reduzir tensões, ansiedades, emoções negativas e autocensura.

Os estudiosos do tema apontam características que se fazem presentes nesse contexto, tais como, acontecer de forma solitária, mecanismo de enfrentamento desadaptativo, alívio momentâneo, sinalização de um grande sofrimento psíquico que não é verbalizado e com consequências tanto físicas como psicológicas, não só para os sujeitos que vivenciam tal condição, mas também para familiares e pessoas próximas (REIS et al., 2013; MONTEIRO, 2012; FROTA et al. 2018).

Segundo o Ministério da Saúde (2014), “não há produção de saúde sem produção de saúde mental". Portanto, a ampliação de pesquisas voltadas para a dimensão biopsicossocial é significativa para o futuro saudável do indivíduo que vivencia tal condição, diante de um período turbulento que gera emoções, vivências e episódios importantes as quais não tem condições psíquicas suficientes para passar. A violência autodirigida parece ser apreendida como uma das formas de enfrentamento aos sofrimentos psíquicos vivenciados (REIS et al. 2013).

A automutilação é apresentada com alguns sinônimos pelos estudiosos do fenômeno, tais como autoagressão, autolesão, cutting, dentre outros. No entanto, nesse artigo, utilizaremos o termo automutilação para melhor compreensão do que está sendo analisado.

Os autores, estudiosos da temática, apontam que as condições de automutilação são conhecidas como via de exteriorização de uma dor e sofrimento, mas quando ocorrem, de forma sucessiva, por períodos prolongados estão associados ao aumento no risco de ideação e tentativas de suicídio. Pode também, em casos mais graves e com episódios frequentes e intensos, ocasionar morte acidental, quando o ferimento é mais grave que o planejado. Tal fato já reforça a necessidade de um maior foco de estudos dessa temática. 
Quando acontece com adolescentes, deve-se ter uma percepção mais ampla do contexto, pois tais comportamentos acontecem em uma das fases de desenvolvimento com extremo significado, perpassado por mudanças de grande abrangência e que pode ter consequências ainda mais amplas no desenvolvimento desse sujeito. Assim, o objetivo do estudo foi compreender melhor as condições e relações existentes entre os comportamentos de automutilação em adolescentes, detalhar o perfil, condições psíquicas e sociais. Compreender esse fenômeno com objetivo de propor formas de prevenção a esses comportamentos.

A pertinência dessa pesquisa está na contribuição para a compreensão de um tema contemporâneo, especificamente no contexto da instituição escolar. Na Instituição pesquisada os casos de automutilação estavam ocorrendo de forma frequente, fato que levou os professores e diretoria do local a buscar ajuda de profissionais da área de saúde mental para compreensão do fenômeno, apontando que diante da apreensão pode-se buscar a prevenção e sensibilizar os adolescentes para que busquem uma configuração mais assertiva de demonstração e elaboração de seus conflitos psíquicos (FROTA et al. 2018).

É um desafio, para os profissionais que lidam com indivíduos que se automutilam, o entendimento desse fato tão complicado, ocorrência complexificada, quando ocorre em instituições escolares e os professores ficam inertes diante de algo que não conhecem, diante de uma realidade a qual não estão preparados para lidar.

Segundo Silva e Santos (2016) inquietações e investigações na busca do entendimento das condutas de automutilação vêm ocorrendo nos últimos anos e o número de estudos científicos e clínicos foram ampliados desde meados do ano 2000, no entanto insuficientes diante da realidade abrangida. As descobertas são significativas para entendimento desse fenómeno considerado contemporâneo, mas que existe historicamente em sociedade. No entanto, muitas questões relacionadas a amplitude do fenômeno e sua interação com a fase da adolescência precisam ser melhor compreendida.

Por exemplo, Giusti (2013) indica que o comportamento de automutilação ocorre de forma episódica e individual, mas que pode tornar-se recorrente, acrescendo em frequência e intensidade, diante da inabilidade em lidar com sofrimentos psíquicos e controlar o comportamento. Mas, tal afirmação, não deixa claro a condição de contágio que é apontada por muitos autores como relacionada à automutilação em grupos de 
adolescentes. Contexto este que necessita de uma ampliação de estudos para entendimento dessa condição. Compreender os mecanismos psíquicos envolvidos nesse fenômeno auxiliam na construção de formas de intervenção e prevenção, além da possibilidade de inserir hábitos adaptativos que possam substituir o comportamento de agressão a si mesmo.

A pesquisa foi aplicada em Escola Pública, localizada no município de Fortaleza - Ceará, com relatos de muitos adolescentes que cometiam a automutilação. A diretora da escola procurou auxílio em Instituição de formação universitária de curso da área de saúde, dentre eles Psicologia, Enfermagem, Serviço Social para intervenção. No entanto foi necessário a aplicação de uma pesquisa para entendimento da realidade escolar, bem como conhecimento dos perfis dos estudantes envolvidos em tais comportamentos, pesquisa aplicada por uma profissional da área de Psicologia. A metodologia utilizada foi grupo focal com os professores e diretoria, com análise de conteúdo dos discursos apresentados durante a realização do grupo.

O artigo está dividido em seções que auxiliam no processo de compreensão da automutilação. Além da introdução, tem-se o referencial teórico com definições e estudos atualizados sobre a adolescência e a automutilação, seguido da metodologia empregada para a pesquisa e os resultados alcançados, com a descrição do que foi analisado na instituição pesquisada, as categorias encontradas e as propostas possíveis para buscar auxiliar professores e estudantes diante desse fenômeno.

\section{OS ADOLESCENTES E A AUTOMUTILAÇÃO}

\subsection{A adolescência}

A Adolescência é um tema discutido amplamente no meio científico, levando em conta os aspectos psíquicos, biológicos, sociais, históricos e culturais que definem essa fase de desenvolvimento. Um fator importante, indicado pelos autores para a compreensão dessa fase, é a sugestão de um contexto conflituoso e difícil tanto para o adolescente, como para a família, escola, amigos e demais pessoas que lidam diretamente e indiretamente com ele. No entanto, alguns autores apontam a condição de adolescer como um fenômeno com aspectos mais relacionados ao contexto cultural, sociopolítico e histórico, com contextos significativos que o definem, tais como: período crítico, 
conturbado por redefinições de natureza existencial (MATHEUS; EISENSTEIN, 2006; CHECHIA, 2010; SCHMIDT, 2001; OZELLA, 2002).

Assim, a adolescência é considerada um constructo histórico e social e para sua compreensão é preciso entender a concepção preponderante em um determinado período histórico e social em que os adolescentes estão inseridos (CHECCHIA, 2010). Ocorre uma representação, enquanto fato social e psicológico, formatada, com base nas necessidades sociais e econômicas, com características que emergem ao longo de sua constituição e influenciam o contexto de seu futuro (OZELLA, 2002).

Os conceitos de juventude e adolescência indicam fenômenos históricos e sociais (não existem do mesmo modo em todas as épocas históricas e em todos os meios de uma determinada sociedade), com diversidades internas (os segmentos juvenis de uma mesma geração podem ser, em algumas dimensões, tão diferentes entre si quanto de uma geração para outra), mas cujos componentes compartilham elementos culturais e atitudinais comuns, próprios da sua geração (SCHMIDT, 2001, p. 186).

Portanto, não se pode afirmar que existe uma única forma de compreender a adolescência, diante da pluralidade de condicionantes envolvidos em sua contextualização, existindo diversas formas de experenciar essa fase de desenvolvimento. Ponderando a complexidade social e psicológica justifica-se conhecer as conformações atuais na sociedade influenciadoras de comportamentos, pensar, agir e ser desse adolescer (CHECCHIA, 2010). Tal aspecto contribui para a apreensão dos aspectos envolvidos com o fenômeno, oferecendo informações significativas para questionamentos e explicações dessa realidade.

Henriques (2018) analisa que na sociedade atual existem condições que influenciam cobranças e pressões pessoais e sociais, aspectos de resiliência são solicitados, no que tange ao desenvolvimento e inserção social, e o alcance de uma posição social diferenciada, assim como para a conquista precoce financeira, profissional, afetiva e pessoal, dentre tantas outras. Os adolescentes sofrem pressão familiar, escolar e social, além da pressão pela normalização e disciplinarização de comportamentos e corpos e essas condições desencadeiam diversas formas de enfrentamento.

Para Berni e Roso (2014) é um período vivenciado entre a infância e a adultez, caracterizado por mudanças físicas, psíquicas e sociais, com transições diversas, mudanças comportamentais significativas que afetam o momento vivenciado, bem como influenciam a saúde geral e o bem-estar da posterior fase adulta Nessa etapa do ciclo de 
vida surgem outros papéis e as modificações exigem uma reorganização psíquica, com expectativas conflitantes (VAN DE GRAAF, 2003; GASPAR; LATERZA, 2012).

Para Levisky (1998) a adolescência é caracterizada pela revolução biopsicossocial, um processo sócio histórico surgindo com a industrialização e o incremento da burguesia. Mas, é importante frisar aspectos intrínsecos desse processo, tais como o adolescer ocorrer em concomitância com a puberdade, fase de transformações biológicas decorrente da maturação biofísica dos indivíduos. Além de estar relacionada a fatores extrínsecos e regionais, mesmo diante de aspectos que podem ser considerados universais.

No entanto, existem aspectos que ficam claros na busca de entendimento da adolescência. Para Aberastury e Knobel (1989) deve ser considerado natural a busca de identidade, tendência a participação de grupos, necessidade de fantasiar e intelectualizar, atitude social reivindicatória, contradições excessivas nas manifestações de conduta, separação progressiva dos pais, flutuações de humor e do estado de ânimo, fatos definidos como sinais da síndrome da adolescência normal.

Ainda é importante salientar que não é uma tarefa simples os marcadores etários da adolescência. Levando em conta os aspectos legais dessa demarcação, tal fato fica ainda mais complexo. De acordo com o Estatuto da Criança e Adolescente -ECA a adolescência é demarcada dos 12 anos completos aos 18 incompletos. Para a Organização Mundial de Saúde - MS, adolescência começa aos 10 anos e termina aos 19 anos completos. A Organização da Nações Unidas - ONU demarca entre os 15 e 24 anos e o Ministério da saúde de 10 a 24 anos. E tais definições não consideram aspectos de desenvolvimento psíquico, cultural e social que não são facilmente percebidos ou claros de definição e que influenciam direta e indiretamente o processo do adolescer.

Arnett (2010) distingue que o início da adolescência está vinculado às primeiras manifestações da puberdade, com término delimitado por fatores incertos, tais como: fim dos estudos, capacidade de estabelecer relações íntimas e independência econômica. Mas, de um modo geral, a adolescência transcorre entre os 10 e os 18 anos de idade (ARNETT, 2010; PAPALIA; FELDMAN, 2011).

Levisky (1998) aponta que a puberdade é coberta de transformações biológicas, hormonais e funcionais com modificações corporais que adquirem significado fundamental na vida do adolescente, refletindo na vida emotiva do jovem em processo de 
adolescer. "A medida que o corpo vai adquirindo nova configuração, a imagem mental que o adolescente tem de si vai se modificando. Porém, a velocidade com que ocorrem as transformações físicas difere daquela relativa às transformações da imagem corporal" (LEVISKY, 2008, p.47).

Ocorrem transformações incontroláveis e involuntárias além de variadas perdas com as quais deve aprender a lidar: perda do corpo infantil, perda do papel e identidade infantis, luto pelos pais da infância, mudanças de papéis, considerando-se um período de extremada vulnerabilidade (ABERASTURY, 1983; LEVISKY, 2008). Todas essas condições são desencadeadoras de crises, contextos que influenciam o indivíduo na construção de sua subjetividade e identidade (FROTA; MORATO, 2015). Dentro desses aspectos é significativo frisar os aspectos sociais:

Na sociedade contemporânea, o jovem é acrescido de mais uma função para poder alcançar a condição adulta e ser reconhecido pela sociedade como tal. Ele deve possuir condições para se encarregar de seu próprio destino, qualidade está tão difícil de ser atingida em nossos dias, devido as conjunturas sociopolíticas que as sociedades contemporâneas estão atravessando (LEVISKY, 2008, p.23-24).

Diante da realidade brasileira, as condições de desigualdades sociais influenciadoras de situações de risco e vulnerabilidade de adolescentes, influenciam comportamentos violentos devido a sua exposição diária pela sobrevivência. As incertezas sociais e sobre si agravam a situação de violência como uma ação reativa contra si ou contra outros. (MEIRELLES, HELZOG, 2008).

Para o adolescente as mudanças estão acontecendo no seu corpo, nos contextos familiar e social, em suas habilidades, inserção no mundo, decisões para o futuro, com estabelecimento de uma nova identidade para a vida adulta (BOCK; FURTADO; TEIXEIRA, 2008). No entanto vários autores apontam a importância dessa fase com aspectos negativos e positivos. Nasio (2010) afirma que é uma passagem obrigatória, delicada, atormentada, mas potencialmente criativa. Papallia, Olds e Feldeman (2009) indicam que existem impulsos de desenvolvimento físicos, mentais, emocionais, sexuais e sociais, aspectos que direcionam para sua identidade. Erikson (1976) assinala que é a fase de crise normativa e de desenvolvimento da identidade e formação do ego. Calligaris (2014) aponta que no contexto social existe uma espécie de moratória imposta pela sociedade, cabendo ao indivíduo a responsabilidade em conquistar e desenvolver seu 
espaço e o mundo adulto. Para todos esses processos é cobrado do adolescente a construção de autonomia que leve à identidade do adulto e, para isso, são frequentes os comportamentos de risco, ações com intensidade, repetição e continuidade que o auxiliem nesse processo de elaboração e intensa transformação.

Para Birman (2007) esse conjunto de transformações e diversas condições vivenciadas contribuem para aumentar os conflitos do processo de adolescer, ampliando as possibilidades de subjetivação que passaram a caracterizar o adolescente na contemporaneidade. Guerreiro e Sampaio (2014) confirmam que a adolescência é intensamente influenciada pelo contexto social, mas não deve desconsiderar o processo da singularidade diante da condição de heterogeneidade desta etapa, aspecto que confirma a impossibilidade de um padrão comum e universal adolescente.

Adamo (2008) indica que existe um contexto macroambiental de transformações, com ultimatos intransigentes de adaptação á normas, mesmo diante da sobrecarga de modificações e tensões internas e externas desse sujeito, fato que desencadeia instabilidade e agitação. Modificações de humor, instabilidade emocional, episódios depressivos, condutas difíceis e arriscadas, imprudência e transgressão de regras e comportamentos antissociais possuem interações com o contexto de ações de automutilação, mas que precisam de uma maior investigação para compreensão dessa interrelação.

Giusti (2016) indica que as maneiras de passar por essas emoções e sensibilidade aos afetos são diversas, mesmo diante da menor capacidade de expressão e enfrentamento, com vulnerabilidade aos comportamentos adversos e hostis, assim caracteriza-se esses adolescentes como indivíduos com capacidade de subjetivação reduzida e as respostas vivenciadas são as mais diversas, dentre elas surgem a automutilação. Segundo Breton (2010):

Quebram a mão contra uma porta, queimam-se com um cigarro, se ferem para conter um sofrimento que leva tudo em seu caminho. Ou, em segredo, fazem inscrições cutâneas com um compasso, com vidro, com uma navalha, com uma faca, chocando-se contra o mundo, de maneira a se machucar, recuperam o controle de uma emoção poderosa e destrutiva, eles procuram uma contenção e encontram então a dor ou os ferimentos. Conjuração de impotência por um desvio simbólico que os permite ter controle sobre uma situação que lhes escapa. 
Para Andrioli (2014) regular o afeto diante de uma vulnerabilidade emocional e pouca aptidão em resolver problemas, podem desencadear comportamentos de automutilação diante de situações consideradas intoleráveis, como ansiedade, raiva, depressão, tristeza, fracasso, baixa autoestima. Indica também que pode ser uma forma de autopunição com impressão de um controle interno, na busca de aceitação e expressão de sentimentos angustiantes. No entanto, para entendimento melhor do que seria a automutilação é imperativo a evidência desse fenômeno para abrangência e entendimento do que seriam tais ações.

A automutilação é percebida como uma tentativa de alívio de sensações desagradáveis, conflitos não verbalizados e a continuidade decorre do alívio que sentem, repetindo diante de algo adverso ou até mesmo da lembrança da situação vivenciada. Percebe-se também uma ampliação do comportamento no contexto grupal, principalmente entre jovens, como uma forma de compartilhamento do contexto vivenciado. (REIS et al. 2013).

Nesse assunto é importante o aspecto da vivência escolar, tanto pela importância na vida do adolescente, assim como nesse espaço esses comportamentos podem ser identificados ou apreendidos (LIEBERMAN, 2004). Nesta ótica, considera-se importante destacar esse espaço institucional como potencializador de prevenção e entendimento do fenômeno que é a automutilação.

\subsection{O estudo da automutilação}

A automutilação não é um assunto pesquisado recentemente, muito embora seja um contexto aprofundado cientificamente na atualidade, pois nos últimos anos, este comportamento vem sido ampliado, em maior parte entre os adolescentes, mas não excluindo outras fases de desenvolvimento. O tema tem demonstrando tão significativa importância que foi sancionada uma lei que obriga escolas e hospitais a notificarem casos de automutilação e tentativa de suicídio, a partir da Política Nacional de Prevenção da Automutilação e do Suicídio (BRASIL, 2019).

Muito ainda precisa ser estudado sobre esse fenômeno, considerado de condição multifatorial. No entanto, muitos autores já apontam aspectos específicos sobre o tema. $\mathrm{Na}$ fase do adolescer distinguem-se as vivências próprias da fase, como o isolamento e a dificuldade em estabelecer relacionamentos, levam ao registro psíquico desse sofrimento 
no corpo. Assim como, deve-se distinguir que a automutilação não está ligada a uma tentativa de suicídio ou autodestruição, mas uma busca de autocura e autopreservação (ARAÚJO, SCHEINKMAN, CARVALHO, VIANA, 2016).

Jatobá (2010) indica que é uma das formas utilizadas para marcar o corpo, com ação superficial realizado de forma intencional, modificando ou destruindo uma parte do tecido do corpo, sinalizando o sofrimento psíquico vivenciado e incapacidade para lidar com a situação. As ações ocorrem com incisões, queimaduras, escarificações, cortes e inserções de objetos sob a pele (LE BRETON, 2009).

Transtorno caracterizado por movimentos intencionais, repetitivos, estereotipados, desprovidos de finalidade (e frequentemente ritmados), não ligado a um transtorno psiquiátrico ou neurológico identificado. Os comportamentos estereotipados automutiladores compreendem: bater a cabeça, esbofetear a face, colocar o dedo nos olhos, morder as mãos, os lábios ou outras partes do corpo. Os movimentos estereotipados ocorrem muito habitualmente em crianças com retardo mental (neste caso, os dois diagnósticos devem ser registrados) (ORGANIZAÇÃO MUNDIAL DA SAÚDE, 2008).

A automutilação não deve ser minimizada ou encarada como uma forma do o adolescente solicitar atenção para si, pois sinaliza que o mesmo está vivenciando um momento de fragilidade e perigo, necessitando de suporte para ampliar estratégias ou habilidades de enfrentamento e comunicação (LUKOMSKI; FOLMER, 2007).

Para Strong (1998), Menninger em 1934, historiou sobre a automutilação sob o ponto de vista da Psicanálise, afirmando que essa ação continha três elementos essenciais: agressão retornada para o interior, sentida em relação ao exterior; estimulação, com intenção sexual ou física; e uma colocação autopunitiva para compensar por um "pecado" (STRONG, 1998).

Strong (1998) também afirma que na Psicanalise, Freud nunca utilizou esse termo e nem mesmo referiu sobre esse ato, mas indica que muitas dessas agressões contra si mesmo fazem parte dos destinos possíveis de níveis patológicos e perigosa para a integridade física do sujeito. Considera variadas fontes traumáticas, despertadas por traumas primários ou por violências transgeracionais.

O jovem exterioriza alguma coisa de seu caos interior a fim de vê-la mais claramente, ele reproduz em ato uma impossibilidade de dizer as coisas ou de transformá-las. Onde as palavras falham, o corpo fala, não para se perder, mas para encontrar marcas, restaurar uma fronteira 
coerente e propícia em relação ao mundo exterior (LE BRETON, 2010, p. 27).

Os estudiosos do tema trazem definições importantes para compreensão desse fenômeno. Para Almeida et al. (2018) a automutilação é um comportamento disfuncional que busca deliberar situações-problema, diante de insuficientes estratégias de enfrentamento e regulação do afeto, ou seja, formas de adaptação a uma circunstância subjetiva sofrida. Para Giusti, (2013) é um comportamento intencional que envolve autoagressão, sem desígnio de suicídio, onde o sujeito quer mitigar sua dor psíquica, utilizando a autoagressão como uma tentativa de volta ao estado de normalidade e regeneração ao estado normal. Nock (2010) afirma que é uma conduta autolesiva diante de aspectos físicos e psicológicos de sofrimento.

Os autores corroboram com as definições citadas e ampliam aspectos relevantes no estudo da automutilação: comportamento intencional que envolve agressão administrada ao próprio corpo, não socialmente aceita (CARDOSO, 2011); fenômeno heterogêneo associado à aspectos desencadeantes, pertinentes a experiências subjetivas (GIUSTI, 2013) e autoagressividade relacionada a um aspecto íntimo e acobertado (GAUTHIER, 2007).

Este transtorno é indicado como ocorrendo com mais frequência entre jovens e adolescentes, com início entre os 12 e 14 anos (CIPRIANO; CELLA; COTUFRO, 2017). Algumas pesquisas indicam o aumento de casos nos últimos anos, mas com poucos estudos que apontem características de motivação ou consequência. Outro aspecto relevante na atualidade é o contexto da divulgação nas mídias sociais e os casos de pessoas famosas que se automutilam. Tais condições são consideradas influenciadoras do aumento do transtorno em adolescentes e jovens (ALMEIDA et al. 2018).

Para Brown, Fischer, Goldwich e Keller (2017), as mídias sociais, na atualidade, possuem uma configuração de interação social entre os adolescentes, e diante da exposição imagens e de casos na internet, são possibilitados contágios e influências para tais comportamentos. As imagens de automutilação são postadas repetidamente, mostrando ferimentos, com lesões leves ou moderadas e exposição de como fazê-las.

A condição de contágio, definida por Almeida et al. (2018), é a influência dos comportamentos entre as pessoas no mesmo grupo. Os adolescentes com familiares ou 
colegas que cometem esse tipo de ação contra si têm maior chance de repetir tal comportamento, tendo a tecnologia o papel de potencializar e espalhar esta tendência.

A automutilação é desencadeada, geralmente, por problemas ou situações estressantes e que podem ser sucessivos, como: conflitos familiares, rejeições e dificuldades escolares como o bullying, devendo ser analisada como um fenômeno psicossocial que pode ocorrer em qualquer faixa etária, no entanto é mais reiterada no período da adolescência (CARDOSO, 2016), como já apontado por outros autores.

Para Almeida et. al. (2018) a automutilação ocorre mais frequentemente na adolescência decorrente da influência da mídia e redes sociais, pois esses meios de comunicação difundirem tais comportamentos diante de um aspecto comum do adolescer que é o isolamento social, fato facilitado pelas mídias sociais. Aponta ainda que a dependência da internet, o bullying e cyberbullying influenciam o risco de aumento de automutilação, bem como de depressão e suicídio. No entanto, não existem estatísticas que reforcem esta afirmação diante da condição de comportamentos secretos e ainda poucos estudos científicos referentes ao tema.

Le Breton (2010) traz uma interpretação significativa para essa realidade: indica que é uma forma de provocar uma dor a si mesmo, como técnica de sobreviver ao sofrimento. Tendo a condição de ser um meio de sinalização social importante, diante de uma questão subjetiva demandada nos consultórios dos profissionais da área de saúde mental, assim como nas escolas (ARAÚJO et al. 2016)

Mesmo sendo considerado um fenômeno contemporâneo, a automutilação não é uma reação nova, pois está nos relatos históricos, como argumenta Arantagy et al. (2018). Casos de automutilação estão presentes na literatura, tais como citado na tragédia Édipo rei, de Sófocles; no Evangelho, dentre outros. Araújo et al. (2016) cita relatos de casos de automutilação de mulheres com diagnóstico de histeria que perfuravam a pele com agulhas no final do século XIX, trazendo o exemplo do primeiro artigo sobre automutilação, publicado em 1846, com o relato de enucleação de uma viúva maníacodepressiva.

Atualmente a automutilação está incluída no Manual Diagnóstico e Estatístico de Transtorno Mental (DSM - 5) definida como autolesão não suicida, com dano intencional autoafligido à superfície do corpo. Alguns critérios são necessários para o diagnóstico, tais como: sofrimento clinicamente expressivo, conduta autolesiva, alívio de sentimentos 
negativos e de dificuldades interpessoais e percepção de sentimento positivo após as lesões.

Segundo a Classificação Estatística Internacional de Doenças - CID 10 (ORGANIZAÇÃO MUNDIAL DA SAÚDE, 2008) a automutilação compreende movimentos intencionais, recorrentes, estereotipados, envolvendo as seguintes ações: bater a cabeça, esbofetear a face, colocar o dedo nos olhos, cortes, queimaduras, morder as mãos, os lábios ou outras partes do corpo.

Enfim, deve ser vista como:

\begin{abstract}
Automutilação é um problema emocional caracterizado por comportamentos propositais que envolvem agressões diretas ao próprio corpo, mas sem a intenção de cometer suicídio. A intenção de automutilação é aliviar algum sofrimento emocional, sentimentos de raiva, tristeza, angústia, "vazio interno". Emoções sentidas de forma muito intensa, "insuportáveis", fazem com que a pessoa se mutile para sentir alívio dessas sensações (GIUSTI, 2013, p. 9).
\end{abstract}

Segundo Santos e Faro (2018) muitas terminologias são utilizadas nos estudos científicos sobre automutilação, como autoinjúria, autodano, escarificação, autolesão, cutting, caving, dano autoinfligido, conduta e comportamento autolesiva. Guerreiro et.al (2014) indicam também os termos parasuicídio e comportamento suicidário. Le Breton (2010) utiliza o termo escarificação. Para Nock (2010) a heterogeneidade enorme de terminologias pode dificultar o entendimento do fenômeno. Para este artigo foi adotado o termo automutilação como uma forma de identificação e entendimento do estudo.

Existem aspectos importantes para compreensão do fenômeno. Para Giusti (2013) os casos independem de gênero, idade, raça, religião, nível educacional, condição social e econômica ou orientação sexual, ampliando a complexidade e dificuldade de definição do perfil ou prevalência, indicando que o diagnóstico está relacionado ao relato do indivíduo. Os casos incidem em condições isoladas e secretas e tendem à repetição, com cortes em partes do corpo menos percebidas pelos familiares, amigos ou professores, com prevalência três vezes maior em meninas. Fato confirmado por Guerreiro e Sampaio (2013) apontando que o perfil dos jovens que cometem automutilação é mais comum no sexo feminino, assinalando comorbidade com determinadas psicopatologias do âmbito afetivos, tais como borderline, ansiedade, depressão, agressividade e impulsividade. Le Breton (2010) distingue uma explicação para relação com a questão de gênero, afirmando que as lesões corporais são mais comuns nas meninas devido a interiorização cultural do 
sofrimento pelas meninas, assim como os meninos desenvolvem o aspecto de agressão para o exterior.

Couto e Cunha (2017) indicam que os adolescentes com adoecimentos mentais ou uso de substâncias, sem escolaridade, formação profissional e/ou emprego são grupo de alto risco para automutilação. 90\% dos adolescentes que se automutilam apresentam algum adoecimento psíquico e indicam que a automutilação pode ser entendida como um sintoma de alguns transtornos mentais.

Grupos fechados, com adolescentes introvertidos podem trazer como tema a Automutilação antes ou depois das aulas. Nas redes sociais esses adolescentes compartilham suas experiências, apontando as áreas que escolhem para fazer os cortes, sendo principalmente os braços, pernas, barriga e mãos, locais acessíveis e simples de esconder dos pais e professores. Tendo assim a possibilidade de passar de grupo em grupo, efetivando o contagio social pois, além de ensinar e aprender, eles encorajam outros indivíduos a aderirem a essa prática (SILVA; SANTOS, 2016).

Guerreiro e Sampaio (2013) referem aspectos ligados à infância, como experiências traumáticas; separação dos pais; afastamento precoce ou prolongado da família; negligência psicológica; abuso físico e sexual, dentre outros como vivências influenciadoras da automutilação.

Para Vilhena (2016) a automutilação ocorre de forma singular posta no corpo e contorno dos cortes. As lesões superficiais são feitas em lugares de fácil acesso, com suas cicatrizes escondidas, perpassado por sentimentos de vergonha e arrependimento. Utilizase tesouras, giletes, cacos de vidros, pedaços de madeiras ou qualquer outro objeto que possa causar lesões (ALMEIDA et el. 2018).

Para os profissionais que atendem adolescentes que cometem automutilação as queixas são difusas, como apontam Vilhena (2016), sem contextos orgânicos evidenciáveis, mas com discursos de extrema angústia, relatos de somatizações, dores no peito, dormência e mal-estar em geral, com ações além dos cortes, como cabelos arrancados, unhas e peles de dedos comidos e ferimentos em diversas partes do corpo.

A automutilação abrange uma ampla gama de comportamentos, incluindo: cortes superficiais; queimaduras; arranhões; mordidas; bater certas partes do corpo contra a parede ou objetos; contundir ou fraturar 
ossos; interferência no processo de cicatrização de ferimentos, com consequente aumento; arranhar e escavar a própria face, acompanhado de sangramento; infectar-se; inserir objetos em cavidades do corpo; puxar cabelos, além de esfregar pedaços de vidros na pele e outros, sempre realizados com a intenção explícita de causar danos ao organismo. (ALMEIDA, 2018, p. 150).

As razões para os atos de automutilação são indicadas por Nock (2009) como um pedido de socorro e comunicação de uma dor, especialmente quando ocorre com adolescentes mais introspectivos. O resultado da ação é um alívio imediato, amenizando o sofrimento psíquico, mas com rápido retorno, daí a necessidade de repetição, por períodos prolongados, diante da não resolução, mas sim apenas amenização do sofrimento.

Para Le Breton (2006, p. 2) ocorre a busca de domínio sob uma condição que resiste ao controle, assim ao se infligirem dor, inventam um controle diante de um sentimento de desespero e de desorientação, "como uma forma de hemorragia de sofrimento que destrói os limites de si”. O corte é uma experiência de controle, uma diminuição do sentimento de mal-estar.

O corte no corpo é uma forma de tentar barrar o sentimento de colapso. $\mathrm{O}$ choque de realidade que ele induz, a dor consentida, o sangue que corre religa os fragmentos esparsos de si mesmo. Permite que haja uma reintegração e alimenta o sentimento de se estar viva, de restabelecimento das fronteiras de si (LE BRETON, 2006, p. 5).

Na automutilação a dor física libera o desvio da tensão psíquica intolerável, sendo o aspecto emocional motivador das ações. Giusti (2013) aponta que a ação é seguida pela sensação de bem-estar e alívio, no entanto, retornando os sentimentos angustiantes depois, pois a dor do corte, a visão da ferida, seus traços e a visão de sua cicatrização podem acalmar a dor por períodos curtos.

Almeida et al. (2018) afirmam que as ações de automutilação têm como origem uma dor silenciosa com crescente tensão e sensação de perda de controle, com sensação de rejeição ou abandono, culpa, vazio e sensação de inutilidade. Parks (2011) indica que a ação de automutilação é impulsiva diante de sentimentos de raiva, ansiedade ou medo que não são verbalizados ou expressos. Como o alívio é momentâneo, diante da sobrecarga emocional, procura-se um novo alívio, fato que desencadeia mais atos lesivos em frequência e alcance. 
No tocante aos fatores de risco, diante de uma realidade multicausal, aponta-se uma vulnerabilidade biológica, assim como fatores sociais e psicológicos conexos, indicado assim como um fenômeno biopsicossocial. Uma personalidade impulsiva e agressiva, com instabilidade emocional possuem fácil adesão a condição de automutilação, principalmente na adolescência. Aspectos como insegurança, impulsividade, baixa autoestima e pessimismo também são traços psicológicos considerados frequentes nos indivíduos que cometem automutilação (ALMEIDA, et al. 2018).

Fatores biológicos e alterações bioquímicas exercem papel proeminente nestes casos. Citam ainda aspectos como insônia, fadiga, doenças ou anomalias da tireóide ou hormonais, síndrome pré-menstrual, ingestão de substâncias psicoativas são consideradas condições de risco para o engajamento em comportamentos autolesivos. O estresse psicológico é estimado como um fator associado, diante da realidade de que causam danos a si mesmo como forma de lidar com essa condição. Alude ainda fatores como vulnerabilidade intrapessoais (emoções e cognições aversivas e baixa tolerância ao distresse), como interpessoais (baixa habilidade de comunicação e capacidade de resolução de problemas) (NOCK, 2010).

Para Almeida (2018) o comportamento episódico pode se tornar repetitivo, com procura por contato com pessoas que se automutilam e acréscimo da gravidade das lesões. Surge a precisão de maior proporção e gravidade para obtenção do mesmo sentimento de alívio inicial e um maior distanciamento para ocultamento das marcas e cicatrizes. Pode tornar-se crônica, com dependência das lesões para o alívio desenvolvendo um ciclo vicioso que demanda tempo, desencadeando diminuição de atividades familiares, sociais e escolares.

Diante de todos esses aspectos apresentados, o contexto escolar é um espaço significativo nesse processo de mudança da adolescência e também nas condições de automutilação. Para a presente pesquisa o contexto escolar é considerado relevante quando o assunto automutilação surge. As instituições escolares são consideradas espaços de reverberação de um discurso de competição, normatização, exclusão e conteúdos desencadeantes de práticas permissivas e autoritárias, fato que coloca o aluno em uma posição de desconforto e enfrentamento de condições com as quais não possui estrutura 
psíquica para lidar com essa realidade, influenciada pelo contexto de crescentes modificações as quais o adolescer proporciona.

E surge uma questão significativa nesse universo escola que influencia no contexto da automutilação: ocorre uma maior propensão de haver bullying ${ }^{1}$. Segundo Bandeira e Hutz (2012) é uma prática antiga, invisível e que costuma ter como motivação formas de preconceito, em especial quando está relacionada as diferenças relacionadas à aparência. Acontecem atos considerados corriqueiros como apelidos estigmatizantes, perseguições, exclusões e até ações de violência física e psicológica. O bullying está relacionado às diferenças de poder que ocorrem de forma sutil e silenciosa, condenando os mais fracos e frágeis ao isolamento, com consequências danosas, podendo chegar inclusive ao suicídio, sendo citado também como motivador para a autoagressão.

Diante de tantas informações e detalhes decorrentes do processo de adolescer e sua interpelação com automutilação é necessário a ampliação de estudos sobre a temática, com objetivo de aprofundar o conhecimento sobre o fenômeno. Percebe-se a necessidade de estudos científicos que ampliem as relações de situações e condições que interferem no entendimento do fenômeno multifatorial que é a automutilação na adolescência.

\section{METODOLOGIA}

O estudo teve como base o modelo exploratório, analítico, descritivo e transversal tendo como objetivo a compreensão de uma realidade particular, propondo discutir e refletir teoricamente sobre a adolescência e a condição de automutilação, tendo como pano de fundo o estudo de caso de um contexto escolar.

A pesquisa, construída segundo uma perspectiva qualitativa, buscou questionar suposições e ideias de professores sobre um fenômeno percebido em seus cotidianos de trabalho junto à adolescentes. Para tanto iniciou-se um estudo bibliográfico sobre o referido fenômeno, bem como as possíveis interrelações existentes entre ele. Com a base teórica foi possível o desenvolvimento de uma pergunta de partida, aplicada em grupo focal, com diretoria e professores da escola pesquisada, posteriormente sendo aplicada uma entrevista semiestruturada com a diretora objetivando obter informações aprofundadas sobre o perfil dos casos e de alunos adolescentes que cometem automutilação. Os dois métodos utilizados tiveram como objetivo focalizar a pesquisa e 
integrar os resultados apresentados. Nesse sentido, o estudo de caso instrumental único aprofundou um contexto contemporâneo da vida real (YIN,2009)

O grupo focal foi formado com dez professores, com objetivo de facilitar o encontro dos participantes da pesquisa e promover a discussão sobre a temática. Vale ressaltar que em relação ao tamanho ótimo para um grupo focal é indicado uma quantidade entre seis e dez pessoas, sendo uma quantidade que permita a participação efetiva dos integrantes e a facilitação adequada da discussão dos temas (PIZZOL, 2004).

A escola pesquisada surgiu como um caso especifico de contexto de automutilação diante da demanda por orientação a uma universidade particular de Fortaleza. A diretoria solicitou uma palestra relacionada às condições de mudança na adolescência, bem como condições de automutilação. Com a solicitação surgiu a oportunidade de realizar uma pesquisa para compreensão do fenômeno, assim como poder lançar propostas de prevenção à situação.

O grupo focal buscou proporcionar a valorização da escuta dos conteúdos do discurso do professor, propondo uma condição de pesquisa exploratória e descritiva. Um espaço privilegiado de discussão e permuta de experiências diante do contexto diretivo em torno da temática apresentada. A partir da pergunta disparadora houve uma ampla discussão sobre as condições relacionadas a automutilação. Seu formato estimulou o debate entre os participantes, permitindo que o tema fosse problematizado mais amplamente que numa situação de entrevista individual. Todo o conteúdo foi gravado para posterior análise de conteúdo do discurso levantado.

Como normativa de pesquisa com seres humanos e seguindo o Conselho Nacional de Saúde -CNS, com a resolução no 510/2016 do Conselho Nacional de Saúde (BRASIL, 2016), a pesquisa foi encaminhada e aprovada pelo Comitê de ética de uma Universidade particular de Fortaleza. Foram aplicados os Termos de Consentimento Livre e Esclarecido - TCLE em todos os participantes da pesquisa, sendo todos previamente informados do objetivo, procedimentos e riscos da pesquisa, a autorização de gravação das discussões e a omissão de identificação, como também o direito de recusar ou desistir de sua participação sem prejuízo para o mesmo.

Os resultados alcançados forma divididos em categorias para facilitação de entendimento de aspectos relevantes do fenômeno. 


\section{DISCUSSÃO DOS RESULTADOS}

A atualidade é perpassada por várias transformações sociais, culturais e econômicas que afetam diretamente os laços sociais, tendendo a fragilizá-los. Tal fato implica vários posicionamentos decorrentes da avaliação do adolescer na atualidade, numa conjuntura menos favorecida econômica e socialmente, bem como a influência desse processo nos casos de automutilação.

Tais tópicos foram considerados no que tange à realização do grupo focal e das análises das falas. O grupo foi realizado em horários de maior disponibilidade dos professores levando em conta o fato de muitas atividades as quais os mesmos são responsáveis, além da sala de aula. O grupo focal foi formado em outubro de 2018, com um total de 10 participantes, sendo realizada duas sessões, de três horas cada, em dias seguidos, todas no horário vespertino. Essa subdivisão foi decorrente das atividades a serem realizadas pelos professores. As finalizações das discussões foram realizadas diante da saturação dos dados, com repetição de informações.

Os participantes foram selecionados dentro de um grupo de professores que conviviam com alunos que praticavam a automutilação, apresentando conhecimento dos fatores relacionados ao desenvolvimento do fenômeno, sendo assim definida uma amostra por conveniência, diante da realidade escolar. Todos aceitaram participar prontamente do grupo, indicando a relevância da temática e a ampliação de informações sobre este fenômeno tão recorrente na instituição.

No grupo focal não houve dispersão das discussões, diante de uma realidade que se faz presente do cotidiano dos professores integrantes do grupo. Todos conseguiram apontar aspectos que consideravam relevantes para a pergunta inicial proposta. As informações primeiras indicavam que alguns casos já haviam sido cessados e outros casos estavam em andamento, assim a realização do estudo de caso traria informações precisas que não foram perdidas com o tempo diante da realidade ainda em foco, aprofundando o conhecimento sobre o assunto.

Diante da complexidade do tema abordado, o critério de saturação foi sobreposto diante do esgotamento de argumentos e informações novas relevantes, pois os depoimentos ficaram repetitivos e previsíveis; portanto com uma estrutura de significados apreendida (VEIGA; GONDIM, 2001). 
A pesquisadora realizou um papel diretivo, orientando as normas do grupo e aplicando a pergunta inicial facilitadora das discussões: "Qual o perfil dos alunos que cometem a automutilação?”. Centralizando-se na produção de conteúdo, surgiram interfluência dos integrantes no que tange ao tópico perfil, inclusive com aspectos psicossociais que influenciam o fenômeno, identificação de necessidades e expectativas diante de aspectos comuns desses adolescentes. A coleta de informações reuniu informações detalhadas sobre automutilação, perpassando por várias condições internas e externas, a condição de adolescência no contexto socioeconômico e cultural, sendo tal fato apresentado como significativo na realidade desta instituição.

A eficácia dos resultados partiu do alcance de informações qualitativas complexas, com a menor interferência da pesquisadora. Os participantes sentiram-se livres para manifestar suas opiniões, permitindo o acesso ao fenômeno pesquisado, o contexto do caso, cronologia dos eventos, identificação de questões e o perfil dos adolescentes que cometem automutilação.

\subsection{Descrição do caso}

A escola pública de Ensino Médio pesquisada tem dez anos de atuação, localizada na periferia da cidade de Fortaleza. A diretoria percebeu uma demanda referente a automutilação após o comentário de ações de autolesão e uma condição de contaminação entre alunos de outras séries. Nesse contexto buscou-se uma Universidade privada que pudesse atuar como parceira no entendimento desse fenômeno, realizando informes e treinamentos sobre a temática, pois os professores estavam com dificuldades em lidar com a questão $\mathrm{O}$ curso de Psicologia auxiliou na formação de um workshop para os professores e diretoria como forma de conhecimento do adolescer e da mutilação.

Com esse workshop surgiu a necessidade de ampliação de entendimento desse fenômeno sendo assim encaminhado todo o processo de investigação e formação da pesquisa. Após autorização da escola e aprovação do comitê de ética da Universidade iniciou-se o processo de levantamento de dados, sendo aplicado inicialmente o grupo focal e posteriormente entrevista com a diretoria, com objetivo de captar impressões, valorizando dimensões simbólicas e subjetivas dos profissionais atuantes na instituição. A pesquisa foi aplicada a partir de uma amostragem intencional de professores, a partir do relato de casos de alunos adolescentes que cometeram automutilação. 
A escolha do grupo focal e entrevista teve como desígnio o aspecto de múltiplas fontes de informação para posterior análise de conteúdo, sendo assim realizada de forma sistemática e cuidadosa para levantamento dos dados, buscando obter pistas e insights diante da triangulação das informações e validação dos dados.

Segundo levantamentos iniciais, entre o final de 2016 e o início de 2017 foi o período que começou os relatos de mutilações. Não se sabe, ao certo, com quem teve o início, mas houve o relato a partir de duas alunas. Houve, logo depois, um processo de contágio, com relato de diversos outros casos. A partir dessa condição inicial, surgiu uma grande demanda de casos, fato que levou a escola a buscar ajuda para compreensão do fenômeno.

O perfil dos professores indicou variabilidade de gênero e período de experiência no exercício da profissão. Dos 10 participantes seis eram mulheres e quatro homens. Professores de áreas diversas que citavam preocupação relevante diante da condição de sofrimento dos alunos da instituição. Eles serão identificados pelas letras $\mathrm{P}$ e uma numeração após a letra e a diretora com a letra D. Como não foi foco o perfil dos professores, não foram levantados maiores dados referentes aos participantes da pesquisa.

A automutilação levanta questionamentos e enigmas difíceis de serem solucionados, mas muitos aspectos significativos foram alcançados dentro das categorias a seguir: condições sociais do fenômeno, perfil do adolescer e automutilação e características da automutilação.

\subsection{Aspectos significativos da automutilação}

\section{A) As condições sociais do fenômeno}

O contexto escolar estudado é perpassado por vários condicionantes que interferem direta e indiretamente na automutilação. A escola pesquisada está localizado em bairro de periferia da cidade de Fortaleza, sendo identificado pelo grupo como um bairro de elevada situação de pobreza, índices altos de violência e de desemprego, além da implicação com venda de substancias entorpecentes, fatos que sinalizam uma condição importante de vulnerabilização em meio ao processo de desenvolvimento da adolescência, com transformações decorrentes dessa fase. Segundo Ferreira, Sampaio, (2014), devem ser considerados relevantes essas interpelações que existem nos contextos sociais e a realidade escolar. 
São muitos problemas ao redor e não tinha como isso não entrar na escola. Não temos venda de drogas aqui dentro, mas na esquina da escola já presenciamos e isso pode influenciar nossos alunos (P2).

Muitos dos nossos alunos vêm de famílias que passam por problemas: divórcios, desemprego, fome, violência. $\mathrm{E}$ isso vem com eles (P5).

A maioria das alunas só possuem mãe e nenhum contato com o pai. Eles não são presentes e essas mães também tem dificuldades em estar presentes na escola e na vida de seus filhos (D).

Diante das condições vivenciadas também pelos professores, pois muitos deles moram próximo a escola, é importante destacar as condições de despreparo diante de fatos sociais, emocionais e psicológicos dos alunos.

Quando os professores sabem ou descobrem que a mutilação aconteceu, eles não têm suporte emocional e não sabem lidar com a situação, na qual encaminham os alunos a coordenação, mas para mim também é difícil. D

Para nós é difícil. Vivemos muitas condições que eles vivem. Fica difícil entender. P6

O contexto escolar é considerado um espaço significativo para o adolescente, pois assume um espaço diferente, onde o aluno recebe uma proposta de conhecimento e os professores atuam como figuras significativas diante do processo vivenciado. A escola assume um papel de influência nas condições de automutilação, diante da realidade de ações na própria instituição, bem como as condições de grupo e contágio.

Muitos são meus amigos. Contam as dificuldades e situações que passam em seus cotidianos. Alguns eu percebi a automutilação e me perguntei porque não tinha visto antes, talvez pudesse até ter evitado (P5).

Eles gostam daqui, temos baixo índice de faltas e abandonos. E quando faltam nós ligamos para saber o que houve. O envolvimento dos pais é pequeno. Muitos deles mal aparecem aqui na escola, mesmo quando chamamos diante dessa condição de autoagressão. A escola é importante, daí nossa preocupação em ajudá-los (P9).

Sei que poderia ajudar, mas não sei como. Eles gostam de estar aqui e para muitos, esse espaço é de maior tranquilidade e fuga dos problemas. Eles fogem nesse processo de mutilação também (P3).

Adamo (2008) indicou que diante de um contexto macroambiental de transformações, com sobrecargas de modificações e necessárias adaptações às normas, além das tensões internas e externas, ocorrem as instabilidades com modificações de humor, instabilidade emocional, episódios depressivos, condutas difíceis e arriscadas, imprudência e transgressão de regras, com comportamentos antissociais (SCHULTZ; 
SCHULTZ, 2015), inserindo-se as ações de automutilação. A condição social atende a um dos requisitos de condição de sofrimento.

Adolescente é uma fase difícil. Até as definições de aborrecente a gente escuta aqui na escola. Mas a gente entende que é uma fase complicada, com muitas mudanças, inclusive as cobranças que passam. Ter mudança de humor, irritação e algumas tristezas a gente acha normal. Mas a automutilação preocupa (P5).

Eles estão passando por dificuldades: familiares, financeiras de desenvolvimento, de autoconhecimento. Tentamos ajudar, mas com tantas coisas é difícil, para eles e para nós! (P7).

Houve o relatou de ajuda por parte de instituições governamentais enviando profissionais da área de saúde mental para auxílio da condição existente, mas infelizmente os profissionais só estiveram duas vezes no local, conversando com alguns professores, sem conseguir auxiliar nas demandas iniciais dos professores quanto a essa realidade.

Enviaram dois psicólogos para atendimento na área, porém só foram 2 vezes e tudo muito rápido. Sem efetividade. Precisamos ajudar F Foram feitas reuniões de grupos com o título de prevenção de automutilação, porém as informações foram esparsas e limitadas. Precisamos aprofundar esse conhecimento (P1).

A situação não apresentou melhoras até mesmo pela gravidade que se encontra. Foram poucas informações. Acho que não ajudaram tanto. $\mathrm{O}$ melhor seria um tratamento individual, mas é inviabilizado (P4).

Guerreiro e Sampaio (2013) apontam que a adolescência é profundamente influenciada pelo contexto social e tal fato deve ser levado em conta no que tange ao estudo da automutilação em adolescentes. No entanto, o contexto da singularidade não deve ser desconsiderado, aspecto que confirma a impossibilidade de um padrão comum e universal adolescente diante da condição de heterogeneidade desta etapa.

Toda adolescência é difícil e eles vivem numa condição de muitas perdas e precariedade. Esses fatos influenciam essa realidade. A automutilação acontece com os que tem mais problemas (P6).

Nossos meninos e meninas têm muitas perdas. Eles precisam de ajuda familiar, social, psicológica e nossa. Mas, nós também temos dificuldades com todo esse universo. São muitas coisas e a gente tem dificuldade em lidar (P5).

Outro aspecto importante a ser levado em consideração, tais como experiências traumáticas; separação dos pais; afastamento precoce da família; negligência psicológica; abuso físico e sexual, dentre outros são apontados por Guerreiro e Sampaio (2013) como 
fatores relacionados a automutilação na adolescência, além de advertirem que contextos estressores elou traumáticos na família e na infância influenciam tais ações.

Muitos dos alunos que comentem automutilação são filhos de pais separados. Criados só pelas mães e essas passam o dia trabalhando, então eles ficam na casa de parentes, vizinhos, sozinhos ou até mesmo nas ruas. Sem orientação. Daí acontece essas coisas também (P5).

Tem caso de alunos com pais presos, que passaram por abusos e negligências e esses alunos que estão envolvidos com automutilação tem esse histórico. Não dá para fugir dessa realidade da família deles (P3).

Eles têm muitas perdas. Muitos deles nem tem pais, são criados por parentes e sofrem muitas negligências e violências (P1).

O uso da tecnologia e das mídias sociais foram apontados como um aspecto significativo diante desse fenômeno, influenciando os adolescentes.

Todos têm mídias sociais e isso interfere na autoestima deles. Como eles possuem muitas dificuldades e as mídias trazem realidades impossíveis para eles, isso acaba afetando a realidade e levando ao sofrimento $(\mathrm{P} 4)$.

Eles se comunicam muito pelo WhatsApp ou Facebook. Os grupos combinam como será, qual a melhor forma de corte e o local mais calmo para que ninguém da escola veja (P7).

Eles veem muitas coisas que eles não têm e isso interfere na autoestima. Muitos sofrem e demonstram isso diante das falas e as vezes até em condições de atos infracionais. A automutilação também é um sinal (P10).

Fato confirmado por Arantagy (2018) onde a automutilação tende a ocorrer mais frequentemente na adolescência também por influência das mídias e redes sociais, diante da condição de que elas difundem comportamentos e condições de vida que esses adolescentes não possuem, influenciando os aspectos do adolescer e da não realização das condições determinadas nas redes sociais.

A dependência da internet, o bullying e cyberbullying também são aspectos que influenciam essa realidade e ampliam o risco de automutilação, além de depressão e suicídio.

Muitos deles sofrem bullying. E eles acabam sendo excluídos e ficam isolados na sala de aula, na hora do intervalo. E são esses meninos que sofrem bullying que cometem a automutilação (P10).

As redes sociais são cruéis. Influenciam muito nossos alunos. E nem sempre com influências positivas (P2). 
Eles participam de grupos de pessoas que sofrem depressão, que sofrem de anorexia, automutilação. Trocam formas de como cometer suicídio. Tudo isso é muito negativo nessa fase de formação e desenvolvimento (P5).

Diante dessa realidade é importante considerar a condição de contágio definida por Arantagy (2018), como aspectos que influenciam os comportamentos entre as pessoas no mesmo grupo e no caso de adolescentes que comentem automutilação essa realidade está presente.

Eles estão em grupos e repetem comportamentos. Esses grupos são muito perceptíveis e falam muito nessas condições relacionadas a automutilação (P2).

Eles descrevem que participam de grupos que comentam sobre essa ação contra si, todos não fazem só uma vez. Fazem várias vezes ao longo do semestre. E parecem ser sempre as mesmas pessoas (P3).

Assim, a influência e contágio entre os adolescentes e colegas que cometem esse tipo de ação contra si tem maior chance de acontecer e levar à repetição, tendo a tecnologia um papel significativo nesse fenômeno. Como afirma Rosa (2011), grupos fechados, com adolescentes introvertidos podem trazer como tema a Automutilação antes ou depois das aulas. Nas redes sociais esses adolescentes compartilham suas experiências e a possibilidade de efetivação do contágio social encoraja outros a aderirem a essa prática (SILVA; SANTOS, 2016).

"Eles comentam em seus grupos sobre as ações que fizeram, as vezes até nos banheiros da escola. Combinam nos intervalos ou antes e depois das aulas. A gente percebe, mas não sabe o que fazer" (P5). As instituições escolares são consideradas espaços de reverberação de um discurso de competição, normatização, exclusão e conteúdos desencadeantes de práticas permissivas e autoritárias, fato que coloca o aluno em uma posição de desconforto e enfrentamento de condições com as quais não consegue lidar (RIBEIRO, 2016).

“As regras existem nas escolas e as vezes eles não aceitam. A concorrência externa chega aqui, por ser adolescentes eles são cobrados em decidir o futuro, que profissão seguir. E tudo isso é muito difícil" (P5). Percebe-se que muitas condições perpassam a realidade social da automutilação no contexto escolar pesquisado. No entanto, para ampliação do entendimento do fenômeno é necessária uma expansão para compreensão, assim relacionar o desenvolvimento do adolescer e a automutilação é imprescindível. 


\section{b) Perfil do adolescer e a automutilação}

A adolescência é um período bastante estudado pelos profissionais que estudam o processo de desenvolvimento e segundo Berni e Roso (2014) é caracterizado por mudanças físicas, psíquicas e sociais importantes, além das mudanças comportamentais significativas. Surgem novos papéis e uma reorganização psíquica (VAN DE GRAAF, 2003; GASPAR; LATERZA, 2012) e tantas mudanças são influenciadas pelo contexto social. Muitos aspectos são apontados como significativos.

A faixa etária das alunas que cometem automutilação está entre 14 aos 16 anos (P1).

Eles sofrem muitas pressões, são mais meninas, mas também já vi casos de meninos (P3).

Muitas questões de gênero surgem, as influências das redes sociais, os isolamentos. Tudo isso influencia (P6).

A compreensão dessa realidade leva em conta algumas categorias. Para Levisky (1998) a adolescência é envolvida por um processo sócio histórico. A questão de gênero, a exclusão do feminino é significativa para explicar a realidade de mais meninas cometerem essa agressão contra si.

"São casos de meninas e só um caso masculino. As meninas demonstram mais essa dor e sofrimento" (P7). "Só tivemos o caso de dois meninos" (P9). É importante frisar aspectos intrínsecos desse processo, tais como o adolescer ocorrer em concomitância com a puberdade, fase de transformações biológicas decorrente da maturação biofísica. $\mathrm{O}$ adolescer está ligado a fatores extrínsecos e culturais, mesmo diante de aspectos que podem ser considerados universais.

A adolescência é um período de muitas mudanças, todos passamos por isso, mas em períodos diferentes e com influências diferentes. Os hormônios interferem, as mudanças físicas também. É difícil lidar com tudo isso (P10).

Eles precisam de apoio, estão passando por uma fase de muitas mudanças e na atualidade está muito mais complicado. São muitas cobranças (P3).

Para caracterizar o fenômeno devemos levar em conta os aspectos que são comuns a ele, como são apresentados pelos estudiosos da temática, bem como o que é apontado pelos entrevistados na pesquisa. Rodham \& Hawton (2009) afirmam que acontecem que 
forma isolada e secreta, com cortes em partes do corpo menos percebidas pelos familiares, amigos ou professores. Rosa (2011) indica as áreas que escolhem para fazer os cortes, principalmente os braços, pernas, barriga e mãos, locais acessíveis e simples de esconder.

Percebo que eles fazem quando estão sós. Mesmo quando vão em grupo para o banheiro, os cortes são quando estão em espaços sozinhos. Deve ter muita dor envolvida nessa situação (P2).

São cortes em locais que não percebemos facilmente, eles escondem. Mudam o comportamento e se você for atento, dá para perceber (P7).

No contexto social cabe ao adolescente a responsabilidade em conquistar e desenvolver seu espaço e o mundo adulto e essa cobrança leva ao desenvolvimento de comportamentos de risco, ações com intensidade, repetição e continuidade que auxiliam nesse processo de intensa transformação. Daí as repetições e busca de alívios de forma constante (CALLIGARIS, 2014).

São sempre os mesmos adolescentes envolvidos nessa condição de automutilação. A gente até observa se alguém mais entra no grupo deles, com certeza será mais uma pessoa a se cortar (P8).

São muitos aqui. A gente se preocupa e tem outros alunos que vem falar com a gente preocupados também. Nem toda adolescência é igual né! (P4).

Rodham e Hawton (2009) indicam a média de início variando entre 12 e 16 anos de idade, com prevalência três vezes maior em meninas. Fato confirmado por Guerreiro e Sampaio (2013) indicando o perfil dos jovens que cometem automutilação é mais comum no sexo feminino, com comorbidade de psicopatologias do âmbito afetivo. Breton (2010) abaliza sobre a questão de gênero, indicando a interiorização cultural do sofrimento pelas meninas.

Cada aluna tem uma motivação diferente, mas todas elas apresentam baixa estima, sofrem bullying e são introvertidas (P1).

Algumas sofrem bullying sejam por causa da sua aparência, seus gostos, suas subjetividades, se isolam na sala de aula, nos grupos delas (P4).

Problemas de gênero são muitos e recorrentes na escola. A exclusão das meninas é muito frequente, uma questão cultural também do bairro (P9).

Nesse contexto percebe-se que, por meio do corpo, o jovem externaliza suas emoções, condições percebidas com estranheza diante de um turbilhão de transformações, 
muitas vezes não compreendendo claramente o que está acontecendo, desencadeando várias formas de enfrentamento, como a automutilação.

\section{c) Características da automutilação}

As condições de automutilação são diversificadas, bem como suas motivações e o objetivo é, geralmente, um alívio de um sofrimento psíquico. No entanto, é importante saber as peculiaridades e obter dados que possam ajudar na prevenção.

São maneiras diversas de passar por emoções e sentimentos vividos, com menor capacidade de expressar e enfrentar vulnerabilidades e comportamentos adversos (GARRETO, 2015). Esses adolescentes vivenciam dores que não sabem expor, surgindo a automutilação como uma alternativa de alívio. Para Ribeiro (2016) são indivíduos com capacidade de subjetivação reduzida e as respostas às mudanças vivenciadas são as mais diversas. "Sabemos que eles têm problemas. Eles adolescentes precisam de ajuda para superar o sofrimento. Como não consegue só, agem como alívio" (P3). "Ser adolescente é enfrentar mudanças e nem todos tem suporte familiar, social ou psicológico para lidar com essa etapa" (P7).

Existem alguns aspectos que chamam atenção diante da vivência de automutilação, tais como o isolamento, uso de blusas e roupas cumpridas. "O uso da blusa de manga para esconder os cortes, isso foi um padrão visto pela escola" (P5). "Eles mudam o comportamento. Percebemos quando ficam mais distantes e usam roupas que escondem o corpo" (P9).

É importante apontar que a automutilação não está ligada a uma tentativa de suicídio ou autodestruição, mas uma busca de autocura e autopreservação (ARAÚJO et al. 2016). "Houve uma tentativa de suicídio, mas ela falava que queria realmente morrer. Os que fazem o corte não dizem que querem morrer. Eles falam que é um alívio" (P2). "Eles não querem morrer. Eles querem conseguir viver melhor" (P6).

Jatobá (2010) indica que marcar o corpo, com uma ação superficial realizada de forma intencional, sinaliza um sofrimento psíquico vivenciado e a incapacidade para lidar com ele. Considerado um comportamento disfuncional para solução de situaçõesproblema, surge como adaptação a uma circunstância subjetiva sofrida. Como aponta Giusti, (2013) é uma tentativa de busca do estado de normalidade. 
Dentre os motivos para a automutilação foram citados problemas familiares, autoestima baixa e dificuldades nos relacionamentos interpessoais. Os problemas familiares foram citados como significativos diante da realidade social vivida, muitos pais não são presentes no cotidiano dos adolescentes, são distantes, não participam de reuniões ou chamados da escola. Alguns, mesmo sabendo das situações de autoagressão, não tomam atitudes que possam ser consideradas de preocupação ou auxílio aos adolescentes. Os problemas relacionais também significaram aspectos relevantes, especialmente no que tange o nível familiar; conflito, críticas sistemáticas e falta de afeto surgiram como aspectos relevantes. Como apontam Guerreiro e Sampaio (2013), a existência de disfunção familiar tem sido associada a comportamentos autolesivos em adolescentes.

Muitos pais nós chamamos para reunião, para conversar, mas eles não vêm. Dizem que tem muito trabalho, acham que não é nada demais ou que é um comportamento para chamar a atenção (P7).

Os pais são distantes. Não sabem muito da vida dos filhos. Os poucos que comparecem, quando chamados, não imaginam o quanto os filhos podem estar sofrendo. Dizem até que não é verdade o que dizemos (P3).

A automutilação é vista pelos adolescentes como como um modo ou método que utilizam para colocar para fora, refugiar e esquecer os sentimentos que lhe tragam sofrimento, tais como: mágoa, tristeza, ansiedade, raiva, solidão ou alguma psicopatologia como a depressão, visando decompor a dor, de magnitude intolerável, sentida psicologicamente por uma dor visível fisicamente. Os motivos internos e externos podem ocasionar danos na vida destes adolescentes, diante da não possibilidade de mensuração da gravidade que possa ocasionar.

Eles sofrem e não tem apoio para tentar resolver essa dor. Esses cortes parecem ser um alívio para eles (P1).

São muitas questões envolvidas. Muitas cobranças, muitas transformações. Eles encontram uma forma de botar para fora (P10).

A dor física é percebida como mais fácil de sentir do que a dor emocional, pois como aponta Baltazar (2009) este comportamento de autoagressão acalma o indivíduo. Percebe-se como as questões sobre este comportamento são complexas, pois, ao mesmo tempo, o adolescente reproduz um saber, permeadas por mediações que oferecem uma forma de lidar com um contexto psíquico.

Considerando, então, todas as questões apresentadas, pensa-se que a automutilação é um fenômeno complexo, com fortes significados para quem a pratica, e 
muitos questionamentos para quem a estuda. Por conta dessa realidade, uma compreensão não apenas do fenômeno, mas principalmente, do indivíduo por trás dos cortes, surge como uma necessidade premente para ampliação do conhecimento deste fenômeno que está envolvido em tantos contextos e perpassado por tantas questões.

É necessário refletir e analisar diversas questões sobre este comportamento, em outras perspectivas da pesquisa, inclusive levando em conta o próprio sujeito que comete a automutilação. Porque ele tem sido tão comum na contemporaneidade? Como reagem os adolescentes que se automutilam, ao chegar na vida adulta? Quais as condições de tratamento e prevenção mais efetivas? Assim, percebe-se a necessidade de mais amplo foco neste fenômeno e a ampliação de muitas outras pesquisas científicas com essa temática.

\section{CONSIDERAÇÕES FINAIS}

A automutilação tem surgido como um fenômeno que envolve diversos condicionantes que são necessários ampliar pesquisas sobre a temática. O corpo tem servido como instrumento de comunicação, trazendo informações sobre identidade, crenças, valores e aspectos psíquicos e quando as marcas corporais surgem decorrentes de lesões autoinfligidos trazem muitos dados sobre as condições vivenciadas pelo indivíduo, bem como a relação com o sofrimento psíquico e o alívio decorrente das autoagressões.

Decorrente da pesquisa apresentada percebe-se que é necessário refletir sobre a prática da automutilação, principalmente em adolescentes, buscando conhecer mais sobre suas características, refletir sobre o estado de saúde e bem-estar, sofrimento, questões sociais e familiares que perpassam esse fenômeno, sendo um desafio compreender mais sobre a questão. As reflexões sobre estes atos violentos são urgentes e essenciais, diante do cenário atual, com repercussões enormes, incluindo o contexto de saúde pública, sendo tal fato confirmado pela lei sancionada que obriga escolas e hospitais a notificarem casos de automutilação e tentativa de suicídio, a partir da Política Nacional de Prevenção da Automutilação e do Suicídio (BRASIL, 2019).

A automutilação, particularmente em adolescentes, tem sido foco de atenção por parte da comunidade científica. Apesar do maior enfoque e de um maior número de pesquisas voltadas a este comportamento, persistem incógnitas diante da significação da 
realidade vivenciada, daí a necessidade de pesquisar a questão da automutilação sob diversos contextos.

A pesquisa demonstrou a clara necessidade de preparação dos profissionais que atuam junto aos alunos sobre esse universo contemporâneo. Os professores denotaram muita dificuldade em lidar com esse fenômeno tão contemporâneo. O meio social é um tópico que faz parte desse contexto e que precisa ser considerado com uma interação com as condições de automutilação. Buscou-se desenvolver o tema com o intuito de favorecer aspectos de prevenção e bem-estar dos alunos, auxiliando os professores no processo de entendimento da realidade, promovendo projetos de conscientização sobre o tema. A atuação da Psicologia foi voltada, inicialmente, para à oferta de informações, à problematização de situações, com relatos e debate sobre as percepções, sentidos e experiências desses sujeitos, no que tange ao aspecto da automutilação de adolescente na escola, auxiliando-os a refletir sobre a temática e lidar com as dificuldades encontradas no meio em que estão inseridos.

O grupo focal teve um papel de psicoeducação, visto as discussões acontecerem a partir de uma realidade que todos vivenciam e a qual todos demonstraram suas angustias diante da realidade comum a todos. A escuta dos alunos e auxilio nessa etapa surgiu como uma máxima necessária ao contexto, além de todos apontarem a necessidade de busca de mais informações para assim poder auxiliar seus alunos.

A pesquisa apontou que a automutilação na adolescência é fenômeno relevante, perpassado por várias condições, atingindo a sociedade como um todo, incluindo os professores e educadores que acompanham cotidianamente os adolescentes em suas atividades escolares,

As categorias encontradas trazem dados que apontam a necessidade de maior percepção do processo do adolescer, levando em conta o contexto social, a influência das mídias socias, a importância dos grupos e do contexto escolar. A prática da Automutilação se mostra um relevante problema que demanda uma visão holística, considerando suas variações e motivações, além das idealizações subjetivas e as influencias psicossociais

$\mathrm{O}$ fenômeno tem atingindo contextos mais amplos diante da internet, ferramenta que tem sido utilizada como referência de informações, grupos, reforço de estigmas e comportamentos de risco. Diante dessa realidade é significativo apontar que poderiam ser utilizada estratégias de prevenção e promoção de saúde 
Assim, existem alguns aspectos sociais importantes para o entendimento deste fenômeno. $\mathrm{O}$ fato de acontecer na fase da adolescência traz aspectos significativos dessa fase, tais como isolamento e dificuldades de relacionamento, além das condições intrínsecas de ocorrência do bullying. As vivências em grupos são significativas, além da valorização dos pares a condição de contágio que é apontada como aspecto de relevância no contexto pesquisado. E a importância da tecnologia como contexto potencializador e facilitador da disseminação desse comportamento. Tais condições devem ser considerados quando diante desse fenômeno, como fator de conhecimento e acompanhamento de suspeita ou comprovação de ações contra si mesmo na fase da adolescência.

Ademais, tendo em vista que não é um fenômeno novo, é fundamental que este problema seja compreendido como sendo configurado a partir dos condicionantes histórico-sociais que permeiam a experiência do que é ser adolescente. Ainda há muitas lacunas existentes, além de vertentes deste ato que carecem de estudos mais aprofundados.

O fenômeno necessita de um estudo mais ampliado, fornecendo subsídios propostas de ações preventivas e intervenções buscando a redução de casos de adolescentes que se automutilam. Portanto poder incentivar a conscientização da população-alvo para busca de acompanhamento especializado e no contexto social favorecer a ampliação do conhecimento do fenômeno para que ele não seja tratado como tabu.

Como proposta de intervenção e prevenção propõem-se amplas redes de conversa e facilitação da fala desse adolescentes, pois os professores são reconhecidos como pessoas afetivas e que podem auxiliar nesse processo de transformação social que é o adolescer.

\section{Notas de rodapé}

${ }^{1} \mathrm{O}$ bullying tem como objetivo ferir e magoar um outro, ocorrendo por agressões físicas diretas; agressões verbais diretas e agressões indiretas. Ocorre com persistência e intencionalidade em contextos interacionais dinâmicos. Bandeira e Hutz (2012).

\section{REFERÊNCIAS BIBLIOGRÁFICAS}

ABERASTURY, A.; KNOBEL, M. Adolescência normal. Porto Alegre: Artmed, 1989. 
ADAMO, F.A. Posição depressiva; do sentir ao sofrer. In: SAITO, M.I.; SILVA, L.E. V.; LEAL, M.M. Adolescência: prevenção e riso. 2.ed. São Paulo: Atheneu, 2008.

ALMEIDA, R.S. et al. A prática da automutilação na adolescência: o olhar da psicologia escolar/ educacional. Psicologia: cadernos de graduação ciências humanas e sociais, 2018.

AMERICAN PSYCHIATRIS ASSOCIATION. Diagnostic and Statistícal Manual of Mental Disorders, Fifth Edition. Washington: APA. 2014.

ANDRIOLI, L.P. O corpo na adolescência. Santa Rosa, 2014.

ARANTAGY, E. RUSSO, F.L. GIUSTI, J.S. CORDAS, T.A. Como lidar com a automutilação. São Paulo: Hogrefe, 2018.

ARAÚJO, J. F., SCHEINKMAN D. C., CARVALHO, I. S.; VIANA, T. C. O corpo na dor: automutilação, masoquismo e pulsão. São Paulo, Estilos da clínica, 2016.

ARNETT, J. J. The neglected 95\%: Why American psychology needs to become less American. The American Psychologist, 63(7), 602-614. 2010.

BANDEIRA, C.M.; HUTZ, C.S. Bullying: prevalência, implicações e diferenças entre os gêneros. Psicologia Escolar e Educacional. vol.16 no.1 Maringá Jan./Jun 2012.

BERNI, V. L.; ROSO, A. A adolescência na perspectiva da Psicologia Social Crítica. Psicologia \& Sociedade, 2016.

BRASIL. Ministério da Saúde. Caminhos para uma Política de Saúde Mental InfantoJuvenil. Brasília, 2014.

BOCK, A.M. B.; FURTADO, O.; TEIXEIRA, M.L. T. Psicologias: uma introdução ao estudo de psicologia. 13. ed. São Paulo: Ed. Saraiva, 2008.

BROWN, R. C., FISCHER, T., GOLDWICH, A. D.; KELLER, F. Cutting: Non-suicidal self-injury (NSSI) on Instagram. Psychological Medicine, 2017.

CALLIGARIS, C. A adolescência. São Paulo: Publifolha, 2014.

CARDOSO, C. P. S. Adolescência na voz de adolescentes: bem-estar e comportamentos autodestrutivos, um estudo exploratório. 2011, 55 f. Dissertação (Mestrado em Psicologia) - Faculdade de Psicologia. Universidade de Lisboa, Lisboa, 2011.

CHECCHIA, A. K. A. Adolescência e escolarização: uma perspectiva crítica em psicologia escolar. Campinas: Alínea, 2010.

CIPRIANO, A. CELLA, S.; COTRUFO, P. Nonsuicidal self-injury: a systematic review. Frontiers in Psychology, 2017.

COUTO, D.L. CUNHA, L.S.P. Marcas na pele: A autolesão sob a ótica da Gestaltterapia. Revista IGT na Rede, v. 14, nº 27, 2017. 
EISENSTEIN, E.; MATHEUS, A. T. Fala sério! Perguntas e respostas sobre adolescência e saúde. Rio de Janeiro: Vieira \& Lent, 2006.

ERIKSON, E. Identidade: juventude e crise. Rio de Janeiro: Zahar , 1976.

FROTA, A.M.M.C.; MORATO, H.T.P. Uma compreensão fenomenológica na adolescência a partir de narrativas: Winnicott e a reinstalação do si-mesmo. In: GARRETO, A.K.P. O Desempenho executivo em pacientes que apresentam automutilação. 2015. 223f. Dissertação (Mestrado em Ciências) - Faculdade de Medicina de São Paulo, Universidade de São Paulo, São Paulo, 2015. Disponível em: <www.teses.usp.br/teses/disponíveis/5/5142/tde-06082015-124601>.Acesso em: 15 junho. 2018.

FROTA et al. Atitudes e comportamentos de alunos em situação de violência interpessoal em escolas públicas de um município do Ceará, Brasil In: BRILHANTE, A.V.M. et al. Interfaces entre saúde mental, gênero e violência. Fortaleza: EdUECE, 2018.

GAUTHIER, M. Automutilation et autoérotisme. Topique, 2007.

GASPAR, K.C.; LATERZA, I.D.O. O enlace da adolescência à (con) vivência do câncer: sonorizações da dor. In: ANGERAMI-CAMON. V. (Org.). A Psicossomática e a psicologia da dor. 2.ed. São Paulo: Cengage Learning, 2012.

GIUSTI, J. S.. Automutilação: características clínicas e comparação com pacientes com transtorno obsessivo-compulsivo. Tese de Doutorado em Psiquiatria - Faculdade de Medicinada Universidade de São Paulo, SãoPaulo, 2013.

GUERREIRO, D. F.; SAMPAIO, D.; FIGUEIRA, M. L. Relatório da investigação "comportamentos autolesivos em adolescentes: características epidemiológicas e análise de fatores psicopatológicos, temperamento afetivo e estratégias de coping". Tese de Doutorado em Psiquiatria - Faculdade de Medicina da Universidade de Lisboa, Portugal, 2014.

HENRIQUES, A. A. C. Clima familiar e sintomatologia ansiosa e depressiva em adolescentes: Qual o papel da resiliência? (Dissertação de Mestrado). Retrieved from http://recil.grupolusofona.pt/handle/10437/8812

JATOBÁ, M. M. V. O ato de escarificar o corpo na adolescência: uma abordagem psicanalítica. Dissertação de Mestrado em Psicologia - Universidade Federal da Bahia, Salvador, 2010.93p.

LEVISKY, D. Adolescência: reflexões psicanalíticas. São Paulo: Casa do Psicólogo . 1998.

LE BRETON, D. As paixões ordinárias: antropologia das emoções. Petrópolis: Vozes, 2009. 
LIEBERMAN, R. Understanding and responding to students who self-mutilate. Principal Leadership Magazine. Retrieved from: http://www.nasponline.org/resources/ principals/nassp_cutting.aspx. 2004

LUKOMSKI, J., \& FOLMER, T. Self-mutilation: Information and guidance for schools. Guidance Channel Ezine. Retrieved from: http://www.guidancechannel.com/default. aspx $?$ index $=1328 \&$ cat $=13.2007$

MEIRELLES, Z.; HELZOG, R. A violência na vida de adolescentes e jovens. In: BRASIL. Ministério da saúde. Secretaria de atenção à saúde. Departamento de ações programáticas estratégicas. Saúde do adolescente: competências e habilidades / Ministério da Saúde, Secretaria de Atenção à Saúde, Departamento de Ações Programáticas Estratégicas. - Brasília: Editora do Ministério da Saúde, 2008.

MONTEIRO, A. R.M. et al. Sofrimento psíquico em crianças e adolescentes: a busca pelo tratamento. Esc. Anna Nery, Rio de Janeiro, v. 16, n. 3, p. 523-529, 2018. Disponível em: <http://www.scielo.br/scielo.php?script=sci_arttext\&pid=S141481452012000300014\& lng=en\&nrm=iso>. Acesso em: 11 Jun 2018.

NASIO, J. D. Como agir com um adolescente difícil? Rio de Janeiro: Zahar. 2010.

NOCK, M. K. Self-injury. Annual Review of Clinical Psychology, 6, 339-363. doi: 10.1146/annurev.clinpsy, 2010

ORGANIZAÇÃO MUNDIAL DA SAÚDE. Classificação estatística internacional de doenças e problemas relacionados à saúde CID-10. 5. São Paulo: Artmed, 1999.

PAPALIA, D. E., OLDS, S. W., \& FELDMAN, R. D. O mundo da criança - Da infância à adolescência (11. ed.). São Paulo, SP: McGraw-Hill Interamericana. 2011.

PARKS, P. J. Self-injury Disorder. San Diego, California: Reference Point Press. 2011.

PIZZOL, S. J. S. Combinação de grupos focais e análise discriminante: um método para tipificação de sistemas de produção agropecuária. Rev. Econ. Sociol. Rural, Brasília, v. 42, n. 3, p. 451-468, 2004.

REIS, Dener Carlos dos et al. Vulnerabilidades à saúde na adolescência: condições socioeconômicas, redes sociais, drogas e violência. Rev. Latino-Am. Enfermagem [online]. vol.21, n.2, pp. 586-594, 2013.

SANTOS L.C.S; FARO A. Aspectos conceituais da conduta autolesiva: Uma revisão teórica. Psicol. pesq. vol.12 no.1 Juiz de Fora jan./abr.. 2018.

SCHMIDT, J. P. Juventude e política no Brasil: a socialização política dos jovens na virada do milênio. Santa Cruz do Sul: Edunisc. 2001.

SCHULTZ, D. P.; SCHULTZ, S. E. História da psicologia moderna. São Paulo: Cengage Learning. 2015. 
SILVA, E. P. Q.; SANTOS, S. P. Práticas de ensino, pesquisa e extensão no âmbito do GPECS: problematizando corpos, gêneros, sexualidade e educação escolar. Revista Educação e Políticas em Debate, v. 4, n. 2, Uberlândia, s/m, 2016, p. 1-16. Acesso em 25 Nov. 2016.

STRONG, M. A bright red scream: self- mutilation and the language of pain. London: Penguin Books. 1998.

OZELLA, S. Adolescência: uma perspectiva crítica. In: CONTINI, M. L. J.; KOLLER, S. H.; BARROS, M. N. S. (orgs.) Adolescência e psicologia: concepções, práticas e reflexões críticas. Brasília: Conselho Federal de Psicologia, 2002. p.16-24.

VAN DE GRAAFF, K.M. Anatomia humana. 6.ed. São Paulo: Manole, 2003.

VEIGA, L.; GONDIM, S.M.G. A utilização de métodos qualitativos na ciência política e no marketing político. Opinião Pública. 2001.

VILHENA, J. D. Corpo como tela... navalha como pincel. Revista Latinoamericana de Psicopatologia Fundamental. 2016.

YIN, R. K. Case study research, design and methods. Thousand Oaks. California: Sage Publications, 2009.

\section{Credenciais da autora}

Bastos, Elaine Marinho. Psicóloga e Assistente Social, mestra em Administração. Pesquisadora sobre a temática saúde mental e suas interfaces. Professora universitária na Unichritus e UniAteneu, Fortaleza - CE. Email: psicologia_elaine@ hotmail.com

Endereço para correspondência: Elaine Marinho Bastos. Email:

psicologia_elaine@hotmail.com

Como citar este artigo (Formato ABNT): Bastos, Elaine Marinho. Automutilação de adolescentes: um estudo de caso em escola pública de fortaleza. Educação, Psicologia e Interfaces, v. 3, n.3, p. 156-191, 2019. DOI: https://doi.org/10.37444/issn-25945343.v3i3.167

Recebido: 07/08/2019.

Aceito: 20/11/2019. 